\title{
Evidence for p53 Expression as a Target for Lung Cancer Early Diagnosis
}

\section{Jinguo $\mathrm{Zhu}^{1 *}$ and Qingchen $\mathbf{W u}^{2}$}

${ }^{1}$ Department of Cardiothoracic Vascular Surgery, People's Hospital of San Ya City, Hai Nan 572000, PR China

${ }^{2}$ Department of Cardiothoracic Surgery, the First Affiliated Hospital, Chongqing University of Medical Sciences, Chongqing 400016, PR China

\begin{abstract}
Obiective: To study the change of p53 expression in BEAS-2B cells malignant transformation process, and detect the role of $\mathrm{p} 53$ expression for lung cancer early diagnosis.

Method: BEAS-2B cells acute expose NNK at $500 \mu \mathrm{g} / \mathrm{ml}$ for 24 hours, and these cells (BEAS-2B ${ }_{\text {NKK }}$ cells) were subcultured continuously in vitro, Biological characteristics and ultrastructure of them were studied with Colony formation assay and electron microscopy. The change p53 expression of BEAS-2B cells were detected by immunohistochemical method.

Results: The serum resistance was appeared in the $5^{\text {th }}$ passage of BEAS-2B ${ }_{\mathrm{NHK}}$ cells and these cells could not grow into tumor in nude mice; The plating efficiency of the $15^{\text {th }}$ passage of BEAS- $2 \mathrm{~B}_{\mathrm{NNK}}$ cells in soft agar $(0.032 \%)$ increased 13.9 fold Compared with that of control group cells $(0.0023 \%) \mathrm{P}<0.001$, the cells had the biological characteristic of transformation cells but could not grow into tumor in nude mice; The $25^{\text {th }}$ passage of BEAS-2B cells could grow into tumor in nude mice; The tumor cells were confirmed cancer cells by histopathology. The ultrastructrure also showed that BEAS-2 $\mathrm{B}_{\mathrm{NNK}}$ cells were Transformed into cancer cells. p53 expression of BEAS$2 \mathrm{~B}$ cells were $10.7 \pm 2.3 \%$, but $\mathrm{p} 53$ expression of the 5 th passage of $\mathrm{BEAS}-2 \mathrm{~B}_{\mathrm{NNK}}$ cells were $43.3 \pm 5.7 \%$, the 15 th passage of $B E A S-2 B_{N N K}$ cells were $73.8 \pm 5.2 \%$, the $25^{\text {th }}$ passage of $B E A S-2 B_{N N K}$ cells were $92.4 \pm 6.5 \%$. The $5^{\text {th }}, 15^{\text {th }}$, $25^{\text {th }}$ passage BEAS-2B $\mathrm{B}_{\mathrm{NNK}}$ cells.VS. p53 expression of BEAS-2B cells, $\mathrm{P}<0.001$.

Conclusion: The model of malignant transformation of BEAS-2B cells induced by NNK( $500 \mu \mathrm{g} / \mathrm{ml})$ established successfully. The change of biological characteristic and ultrastructure indicated that the malignant transformation of BEAS-2 $\mathrm{B}_{\mathrm{NNK}}$ cell is a Chronic, multiple-step development process. p53 overexpression appeared early stage in BEAS-2 $\mathrm{B}_{\mathrm{NNK}}$ cells which did not change into cancer cells. It indicated that p53 expression would be as a target for lung cancer early diagnosis, and it was beneficial to early-warning and mass screening of lung cancer in high-risk smoking population.
\end{abstract}

Keywords: p53; NNK; BEAS-2B cells; Malignant transformation

\section{Introduction}

Early diagnosis of cancer is a key factor for the success of treatment. For this reason, identification of highly sensitive and specific novel tumor markers is urgently needed. Research has shown that $\mathrm{p} 53$ gene mutation early events for lung cancer, p53 expression in lung cancer can be used as a marker for diagnosis of lung cancer by many academics. It may contribute to the high risk population of smoking lung cancer early warning and census. But the evidence is not clear. Therefore, in the present study human bronchial epithelial cells (BEAS-2B) were induced malignant transformation by NNK, Establish the model of malignant transformation in vitro, dynamic observation p53 expression in this process, and explore its role and significance in the development of lung cancer.

\section{Materials and Methods}

\section{Reagents, cells line and experimental animal}

NNK was purchased from Toronto Research Chemicals Inc. LHC-8 Serum free medium purchased from American Invotrigion Inc. BEAS2B was obtained from American Type Culture Collection. American patent number: U.S.Pat.4885238. 5 weeks old Nude mice BALB/C-nu/ nu purchased from experimental animal Center of Chengdu.

\section{Cell culture}

BEAS-2B cells incubated with LHC- 8 serum free medium at $37^{\circ} \mathrm{C}$ in $5 \% \mathrm{CO}_{2}$ and $95 \%$ air. Seeding density $1 \times 10^{4} / \mathrm{cm}^{2}$. Replacement LHC-8 serum free medium every 2 days, BEAS-2B cell subculture every 4-6 days. $0.05 \%$ trypsin/EDTA solution (HyClone) was used to perform cell subculture.

\section{Acute NNK exposure}

The BEAS- $2 \mathrm{~B}_{\mathrm{NNK}}$ cell was derived after exposure to the carcinogen NNK for 24 hours at a dosage of $500 \mu \mathrm{g} / \mathrm{ml}$. Then discarded contained NNK of LHC-8 medium, washed three times with PBS and cultured with LHC-8 serum free medium. These BEAS-2B cells are used as experimental group (BEAS-2 $\mathrm{B}_{\mathrm{NNK}}$ ), Control group (BEAS-2B) was not exposure in NNK.

\section{Serum resistance assay}

Harvested the $5^{\text {th }}$ passages exponential growth phase BEAS- $2 \mathrm{~B}_{\mathrm{NNK}}$ and BEAS-2B cells. Dilution at 500 cells per 6 -well tissue culture plate was prepared. There are 6 tissue culture plates in each group. LHC-8 serum free medium was added with $10 \%$ fetal bovine serum in 3 tissue culture plates in each group. After 8 days, the suspended culture was fixed with Formaldehyde for 30 minutes and Giemsa stained. Cell colony number was counted with the microscope (more than 16 cells as a colony). According to the formula: vaccination rate $=$ colony number/ inoculation cell number $\times 100 \%$.

*Corresponding author: Jinguo Zhu, Department of Cardiothoracic Vascular Surgery, People's Hospital of San Ya City, Hai Nan 572000, PR China, Tel: 8618876908139; E-mail: zsjg2009@foxmail.com

Received April 20, 2015; Accepted May 18, 2015; Published May 20, 2015

Citation: Zhu J, Wu Q (2015) Evidence for p53 Expression as a Target for Lung Cancer Early Diagnosis. J Cytol Histol S3:012. doi:10.4172/2157-7099.S3-012

Copyright: (c) $2015 \mathrm{Zhu} \mathrm{J}$, et al. This is an open-access article distributed under the terms of the Creative Commons Attribution License, which permits unrestricted use, distribution, and reproduction in any medium, provided the original author and source are credited. 
Citation: Zhu J, Wu Q (2015) Evidence for p53 Expression as a Target for Lung Cancer Early Diagnosis. J Cytol Histol S3:012. doi:10.4172/21577099.S3-012

Page 2 of 4

\section{Colony formation in soft agar assay}

Harvested the $15^{\text {th }}$ generation exponential growth phase BEAS$2 \mathrm{~B}_{\mathrm{NNK}}$ and BEAS-2B cells. Colony formation in soft agar was plated at 5000 cells/well of BEAS- $2 \mathrm{~B}_{\mathrm{NNK}}$ and BEAS-2B cells from passages 15 in the upper layer $(0.7 \%$ sea plague) of the two layer agar $(0.7 \%$ and $1.2 \%)$ in a $6 \mathrm{~cm}$ tissue culture plate. After 3 weeks, the number of colony (a colony consisted of more than 50 cells) was counted, and clonogenicity (\%o) was calculated as number of colony/total growing cell number $\times$ $1000 \%$.

\section{Tumor formation in nude mice}

Harvested the $5^{\text {th }}, 15^{\text {th }}, 25^{\text {th }}$ passages exponential growth phase BEAS- $2 \mathrm{~B}_{\mathrm{NNK}}$ and BEAS- $2 \mathrm{~B}$ cells. The experimental cells were inoculated $\left(1 \times 10^{7}\right.$ cells/injection) at the left or the right flank subcutaneous of the each nude mouse ( $n=6$ for each group). Tumorigenicity of BEAS$2 \mathrm{~B}_{\mathrm{NNK}}$ and BEAS-2B cells in nude mice were observed for 6 months, and the tumor was collected for further analysis and examined by histopathological.

\section{Cell morphology assay}

Harvested the $5^{\text {th }}, 15^{\text {th }}, 25^{\text {th }}$ passages exponential growth phase BEAS- $2 \mathrm{~B}_{\mathrm{NNK}}$ and BEAS-2B cells. Fixed by $4 \%$ glutaraldehyde and $1 \%$ osmium tetroxide for 2 hours, Alcohol and acetone dehydrated, 618\# epoxy resin embedded, Reichert-Jtmg ultramicrotome performed $0.5 \mathrm{~mm}$ sections. $1 \%$ toluidine blue-azure II stained, Located under the light microscope. Performed Ultrathin sections, Uranyl acetate and lead citrate stained, Observed with electron microscopy.

\section{Immunohistochemistry analysis}

Harvested the $5^{\text {th }}, 15^{\text {th }}, 25^{\text {th }}$ passages exponential growth phase BEAS- $2 \mathrm{~B}_{\mathrm{NNK}}$ and BEAS-2B monolayer cells. rinsed with $1 \times$ PBS three times and immediately fixed in ice-cold Acetone for $5 \mathrm{~min}$. Cells were washed twice with ice-cold $1 \times$ PBS ( 3 min each) and then incubated for $10 \mathrm{~min}$. Cells were washed with $1 \times$ PBS for three times ( 5 min each time) and then incubated with hydrogen peroxide (3\%) at room temperature for $20 \mathrm{~min}$ and goat serum (1.5\%) (Vector Laboratory) in $1 \times \mathrm{PBS}$ at room temperature for $1 \mathrm{~h}$ to block unspecific binding of the antibodies followed by three times washing with $1 \times$ PBS. Cells were then incubated in the diluted p53 antibody (1:50) in goat serum (1.5\%) in $1 \times$ PBS in a humidified chamber at $4^{\circ} \mathrm{C}$ overnight. After three times washing, cells were incubated with diluted biotinylated secondary antibody (1:2000; Vector Laboratory) in $1 \times$ PBS for $1 \mathrm{~h}$. After washing, cells were incubated with VECTASTAIN ABC Reagent (Vector Laboratory) for $30 \mathrm{~min}$. Cells were then stained with diaminobenzidine (DAB; Vector Laboratory) solution until desired stain intensity developed. After washing with tap water, cells were dehydrated in gradient alcohol and cleared in xyline twice ( 5 min each time) and finally mounted with mounting medium. Nucleus or Nucleus and cytoplasm of the cell is brown yellow was positive, only the cytoplasm or no nuclear stained of the cell was negative.

\section{Statistics}

Data are expressed as mean \pm SEM, Significant difference among multiple groups with one variant was determined by one-way ANOVA, every two groups were then compared using Newman-Keuls. The Student $t$ test was used for comparisons between two groups. All analyses were performed using the SPSS 13.0 software. Differences with $p<0.05$ were considered significant.

\section{Results}

\section{Serum resistance response}

The experimental cells serum resistance response shown in Figure 1 . The $5^{\text {th }}$ passage of BEAS-2B cells grew well in serum-free medium and grew inhibition in the medium containing $10 \%$ serum. The $5^{\text {th }}$ passage of BEAS-2 $\mathrm{B}_{\mathrm{NNK}}$ cells growth was not Significant inhibitory In the medium containing $10 \%$ serum. It indicated that the biological characteristics of BEAS- $2 \mathrm{~B}_{\mathrm{NNK}}$ cells were changed, the abilities of proliferation and adaptability enhanced.

\section{Colony formation in soft agar}

The experimental cells anchorage independent growth ability was shown in Figure 2. The $15^{\text {th }}$ passage of BEAS-2B cells grew significantly inhibition in soft agar, but BEAS- $2 \mathrm{~B}_{\mathrm{NNK}}$ cells grew well in soft agar, Clone formation rate of BEAS- $2 \mathrm{~B}_{\mathrm{NNK}}$ cells is 13.9 times of BEAS-2B cells. It has been shown that BEAS- $2 \mathrm{~B}_{\mathrm{NNK}}$ cells had the characteristic of transformation cells.

\section{Tumorigenesis in nude mice}

Tumor formation in nude mice shown in Figure 3. Subcutaneous nodules were observed in BEAS- $2 \mathrm{~B}_{\mathrm{NNK}}$ inoculation nude mice after 7 weeks. Tumors were about $1.5 \times 1.0 \mathrm{~cm}$ after 16 weeks. Tumor examined by histopathological, BEAS- $2 \mathrm{~B}_{\mathrm{NNK}}$ cells change into cancer cells. But the BEAS-2B cells had no Tumors formed in nude mice.

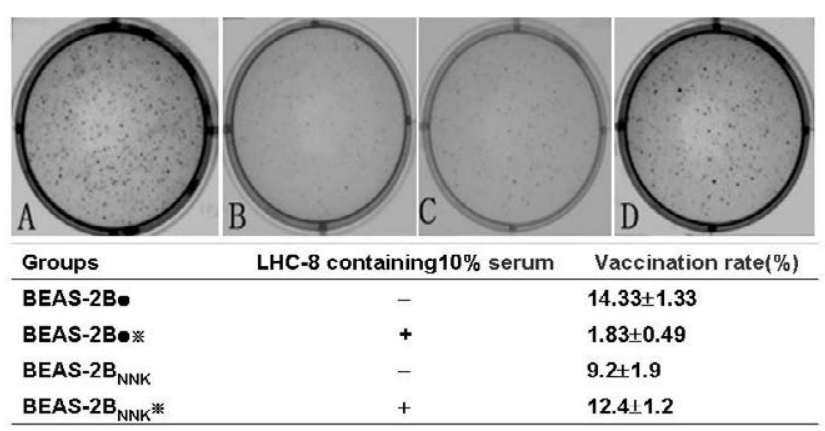

Figure 1: The experimental cells serum resistance response.

+LHC-8 serum free medium added $10 \%$ fetal bovine serum; LHC- 8 serum free medium did not add $10 \%$ fetal bovine serum. A. Response of BEAS-2B cells in LHC-8 serum free medium. B. Response of BEAS-2B cells in LHC-8 serum free medium added $10 \%$ fetal bovine serum. C. Response of BEAS$2 \mathrm{~B}$ cells in LHC-8 serum free medium. D. Response of BEAS- $2 \mathrm{~B}_{\mathrm{N} \text {. }}$ cells in LHC-8 serum free medium added $10 \%$ fetal bovine serum. ${ }^{P} P<0.01 ;{ }^{*} P<0.01$.

A

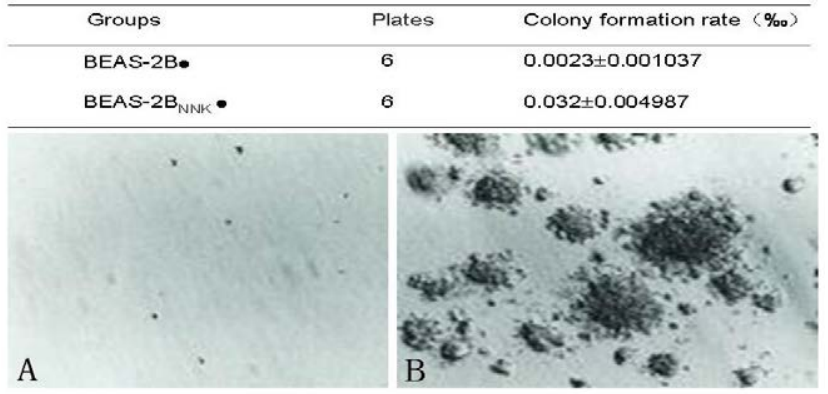

Figure 2: Colony formation in soft agar. A. BEAS-2B cells Colony formation in soft agar. B. BEAS-2B $B_{\text {NK }}$ cells Colony formation in soft agar. Clone formation rate of $B E A S-2 B_{N N K}$ cells is 13.9 times of $B E A S-2 B$ cells. $P<0.01$. 
Citation: Zhu J, Wu Q (2015) Evidence for p53 Expression as a Target for Lung Cancer Early Diagnosis. J Cytol Histol S3:012. doi:10.4172/21577099.S3-012

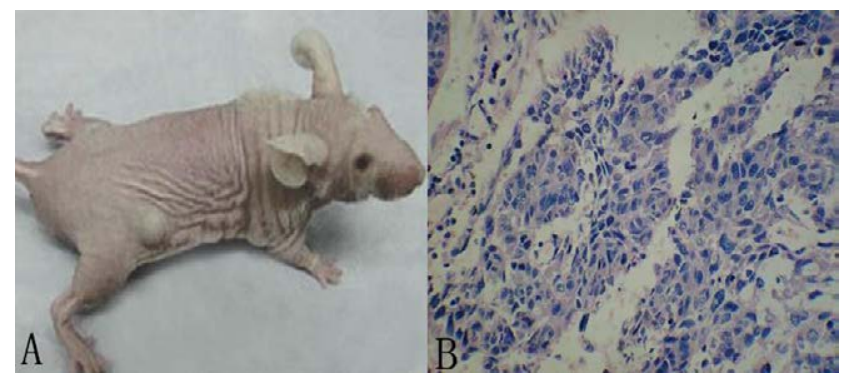

Figure 3: Tumorigenesis in nude mice. A. Tumor in nude mice was about $1.5 \times 1.0 \mathrm{~cm}$ after 16 weeks. B. Tumor examined by histopathological, representative images of $\mathrm{H} \& \mathrm{E}$ staining $(40 \mathrm{X}), \mathrm{BEAS}-2 \mathrm{~B}_{\mathrm{NNK}}$ cells change into cancer cells.
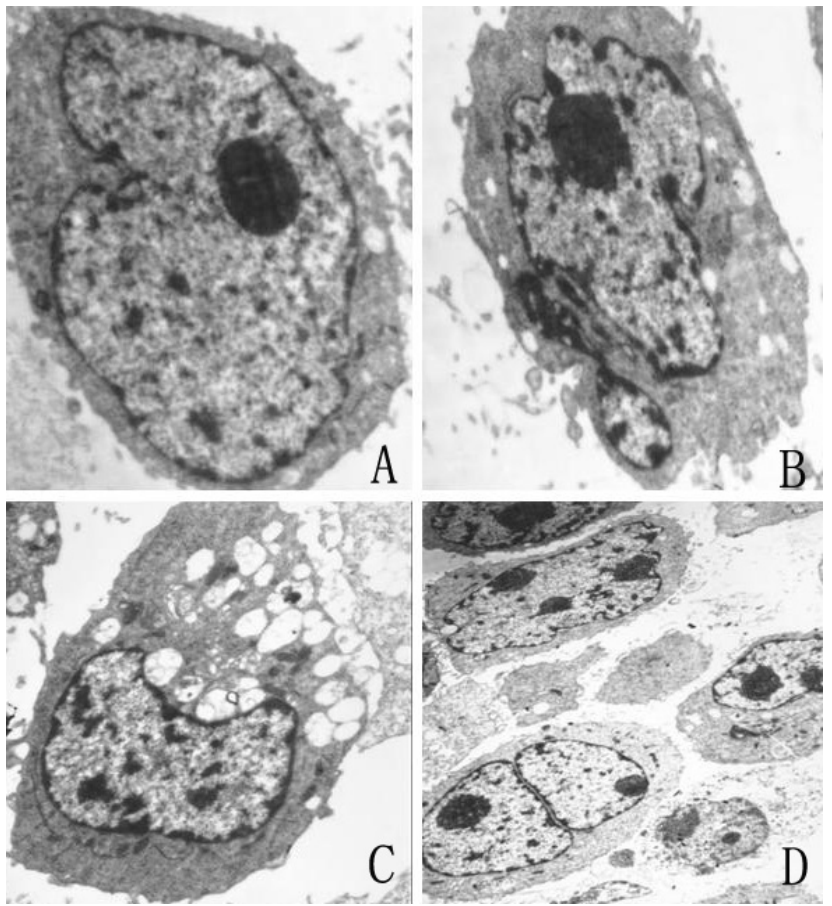

Figure 4: The experimental Cells ultrastructure, Representative images $(3500 X)$. A. The ultrastructure of BEAS-2B cells. B. The ultrastructure of the $5^{\text {th }}$ passages BEAS NNK $_{2}-2 B$ cells. C. The ultrastructure of the $15^{\text {th }}$ passages BEAS $-2 B$ cells, BEAS-2B Cells enlargement, nuclear gradual deformation and fragmentation, nucleus malformation, organelle enlargement and number increased. D. The ultrastructure of the $25^{\text {th }}$ passages BEAS ${ }_{N N K}{ }^{-}$ $2 \mathrm{~B}$ cells, BEAS-2B $\mathrm{B}_{\mathrm{NNK}}$ Cells appeared multiple nucleoli, and had the obvious characteristics of cancer cells.

\section{Cell ultrastructure}

The $5^{\text {th }}, 15^{\text {th }}, 25^{\text {th }}$ passages BEAS- $2 \mathrm{~B}_{\mathrm{NNK}}$ and BEAS-2B cells ultrastructure were shown in Figure 4. Compared to BEAS-2B cells, morphology, number and nuclear of the 5 th passages $\mathrm{BEAS}-2 \mathrm{~B}_{\mathrm{NNK}}$ showed no significant difference. The 15 th passages BEAS-2 $\mathrm{B}_{\mathrm{NNK}}$ Cells enlargement, nuclear gradual deformation and fragmentation, nucleus malformation, organelle enlargement and number increased. The $25^{\text {th }}$ passages BEAS- $2 \mathrm{~B}_{\mathrm{NNK}}$ Cells appeared multiple nucleoli, and had the obvious characteristics of cancer cells.

\section{The result of p53 expression}

p53 expression in the $5^{\text {th }}, 15^{\text {th }}, 25^{\text {th }}$ passages $B E A S-2 B_{\mathrm{NNK}}$ and
BEAS-2B showed in Figure 5. p53 expression of BEAS-2B cells (control group) were $10.7 \pm 2.3 \%$. p53 expression of the $5^{\text {th }}$ passages BEAS $2 \mathrm{~B}_{\mathrm{NNK}}$ cells were $43.3 \pm 5.7 \%$, the 15 th passages BEAS- $2 \mathrm{~B}_{\mathrm{NNK}}$ cells were $73.8 \pm 5.2 \%$, and the 25 th passages BEAS- $2 \mathrm{~B}_{\mathrm{NNK}}$ cells were $92.4 \pm 6.5 \%$. p53 expression of the $5^{\text {th }}, 15^{\text {th }}, 25^{\text {th }}$ passage BEAS- $2 \mathrm{~B}_{\mathrm{NNK}}$ cells.VS. p53 expression of BEAS- $2 \mathrm{~B}$ cells, $\mathrm{P}<0.001$. It indicated that $\mathrm{p} 53$ expression of the BEAS- $2 \mathrm{~B}_{\mathrm{NNK}}$ cells in early stage, with the passages increased, p53 expression was significantly increased.

\section{Discussion}

The major finding in this report is that p53 over expression in BEAS- $2 \mathrm{~B}_{\mathrm{NNK}}$ cells are early stage events, Moreover these p53 over expression cells were not changed into cancer cells. So we inferred that p53 is a good marker for lung cancer early diagnosis. It is beneficial for early-warning and mass screening lung cancer in high-risk smoking population.

4-(methylnitrosamino)-1-(3-pyridyl)-1-butanone (NNK) is a tobacco-specific N-nitrosamine which is considered to play important roles in tobacco-related human lung cancer [1-4]. mechanisms of NNK-induced lung carcinoma have been proposed, including (1) the activation of oncogenes via mutation, (2) interruption and/or silencing of genes encoding enzymes coupled with $\mathrm{NNK}$, (3) direct manipulation of enzymes (specifically from the CYP protein family) responsible for activation and initiation of NNK-mediated processes, and (4) the disruption of the signal pathways [5-7]. In this study, The model of malignant transformation of BEAS-2B cells induced by $\mathrm{NNK}(500$ $\mu \mathrm{g} / \mathrm{ml}$ )can be created successfully. It indicated that NNK-induced lung carcinoma has been proposed. During the BEAS-2B cells Malignant transformed, p53 expression was gradually increased, it indicated that p53 gene was mutant, which showed a very high incidence of multiple early tumors.

The tumor suppressor gene p53 is located on the short arm of chromosome $17(17 \mathrm{p} 13.1)$ [8-13]. The gene spans $20 \mathrm{~kb}$, with a non-coding exon-1 and a very long first intron of $10 \mathrm{~kb}$. The coding sequence contains five regions showing a high degree of conservation in vertebrates, predominantly in exons $2,5,6,7$ and 8 , but the sequences

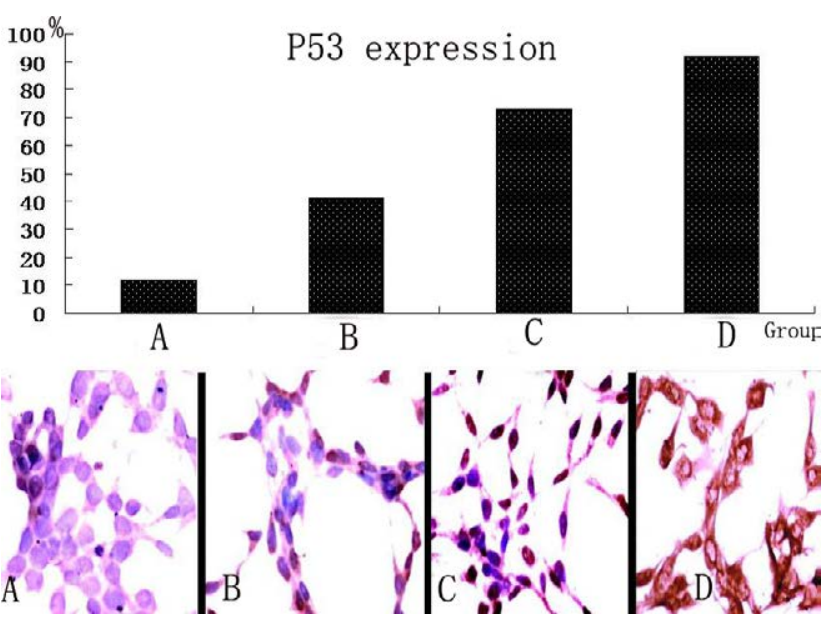

Figure 5: Immunohistochemistry analysis the experimental Cells p53 expression, Representative images (40X). A. P53 expression of BEAS-2B cells were $10.7 \pm 2.3 \%$. B. P53 expression of the $5^{\text {th }}$ passages BEAS-2B ${ }_{\mathrm{NNK}}$ cells were $43.3 \pm 5.7 \%$. C. P53 expression of the $15^{\text {th }}$ passages BEAS-2B cells were $73.8 \pm 5.2 \%$. D. P53 expression of the $15^{\text {th }}$ passages BEAS-2B cells were $92.4 \pm 6.5 \%$. B, C, D.VS.A. $P<0.01$ 
found in invertebrates show only distant resemblance to mammalian p53 $[14,15]$. p53 orthologs have been identified in most mammals for which complete genome data are available [16-19]. p53 has many mechanisms of anticancer function, and plays a role in apoptosis, genomic stability, and inhibition of angiogenesis. In its anti-cancer role, p53 works through several mechansms: (1) It can activate DNA repair proteins when DNA has sustained damage. Thus, it may be an important factor in aging [20-22]. (2) It can arrest growth by holding the cell cycle at the G1/S regulation point on DNA damage recognition (if it holds the cell here for long enough, the DNA repair proteins will have time to fix the damage and the cell will be allowed to continue the cell cycle) [23-24]. (3) It can initiate apoptosis---programmed cell death---if DNA damage proves to be irreparable. Cells that have lost p53 function are likely to be selected during cancer development. In cells expressing a mutant $\mathrm{p} 53$, this protein is generally no longer able to control cell proliferation, which results in inefficient DNA repair and genetic instability. p53-deficient mice are developmentally normal but show a very high incidence of multiple early tumors and generally succumb before reaching the age of 1 year [25-26]. Moreover, when introduced into cells, a mutant p53 can transform and give to these cells a more aggressive phenotype. p53 mutations are the most frequent genetic events in human cancer. They have been found in most types of tumors, with frequencies ranging from $5 \%$ (cervix) to $50 \%$ (lung) [27]. p53 gene mutations can lead to the expression of a dysfunctional protein that in turn may enable genetically unstable cells to survive and change into malignant cells. p53 overexpression has been observed in pre-neoplastic lesions, It is beneficial to the early diagnosis for lung and other tobacco-related tumors.

In this report, BEAS-2B cells were induced Malignant transformation by NNK, p53 expression was increased in different passages, $\mathrm{p} 53$ of the $5^{\text {th }}$ passages BEAS- $2 \mathrm{~B}_{\mathrm{NNK}}$ cells were expression $43.3 \pm 5.7 \%$, Morphological structure of BEAS- $2 \mathrm{~B}_{\mathrm{NNK}}$ cells had no obvious change. But biological behavior of these cells was changed. p53 of the $15^{\text {th }}$ passages BEAS- $2 \mathrm{~B}_{\mathrm{NNK}}$ cells expression were $73.8 \pm 5.2 \%$, Morphological structure of BEAS-2B ${ }_{\mathrm{NNK}}$ cells had obvious change, Cells enlargement, nuclear gradual deformation and Fragmentation, nucleus malformation, organelle cell enlargement and number increased. These cells had the characteristics of transformed cells. And p53 of the $25^{\text {th }}$ passages BEAS- $2 \mathrm{~B}_{\mathrm{NNK}}$ cells expression were $92.4 \pm 6.5 \%$, these cells had already change into cancer cells. The characteristic of p53 being expressed before BEAS- $2 \mathrm{~B}_{\mathrm{NNK}}$ cells changed into cancer cells was beneficial to early diagnose for human lung cancer, so in this study we found the Evidence for p53 expression as a target for lung cancer early diagnosis. At the same time, p53 expression also as a target for early-warning and mass screening of lung cancer in high-risk smoking population.

\section{References}

1. Proulx LI, Gaudreault M, Turmel V, Augusto LA, Castonguay A, et al. (2005) 4-(Methylnitrosamino)-1-(3-pyridyl)-1-butanone, a component of tobacco smoke, modulates mediator release from human bronchial and alveolar epithelial cells. Clin Exp Immunol 140: 46-53.

2. Balbo S, Upadhyaya P, Villalta PW, Qian X, Kassie F (2013) DNA adducts in aldehyde dehydrogenase-positive lung stem cells of $A / J$ mice treated with the tobacco specific lung carcinogen 4-(methylnitrosamino)-1-(3-pyridyl)-1butanone (NNK) Chem Res Toxicol 26: 511-513.

3. Akopyan G, Bonavida B (2006) Understanding tobacco smoke carcinogen NNK and lung tumorigenesis. Int J Oncol 29: 745-752.

4. Chen RJ, Chang LW, Lin P, Wang YJ (2011) Epigenetic effects and molecular mechanisms of tumorigenesis induced by cigarette smoke: an overview. J Oncol 2011: 654931
5. Belinsky SA, Devereux TR, Foley JF, Maronpot RR, Anderson MW (1992) Role of the alveolar type II cell in the development and progression of pulmonary tumors induced by 4-(methylnitrosamino)-1-(3-pyridyl)-1-butanone in the $\mathrm{A} / \mathrm{J}$ mouse. Cancer Res 52: 3164-3173.

6. Maser E, Stinner B, Atalla A (2000) Carbonyl reduction of 4-(methylnitrosamino)1-(3-pyridyl)-1-butanone (NNK) by cytosolic enzymes in human liver and lung Cancer Lett 148: 135-144.

7. Maser E, Friebertshauser J, Volker B (2003) Purification, characterization and NNK carbonyl reductase activities of 11 beta-hydroxysteroid dehydrogenase type 1 from human liver: enzyme cooperativity and significance in the detoxification of a tobacco-derived carcinogen. Chem Biol Interact 144: 435-448.

8. Bargonetti J, Manfredi JJ (2002) Multiple roles of the tumor suppressor p53. Curr Opin Oncol 14: 86-91.

9. Bode AM, Dong Z (2004) Post-translational modification of $p 53$ in tumorigenesis. Nat Rev Cancer 4: 793-805.

10. Gao WM, Mady HH, Yu GY, Siegfried JM, Luketich JD, et al. (2003) Comparison of p53 mutations between adenocarcinoma and squamous cell carcinoma of the lung: unique spectra involving $G$ to $A$ transitions and $G$ to $T$ transversions in both histologic types. Lung Cancer 40: 141-150.

11. Gomez M, Wu J, Schreiber V, Dunlap J, Dantzer F, et al. (2006) PARP1 Is a TRF2-associated poly(ADP-ribose)polymerase and protects eroded telomeres. Mol Biol Cell 17: 1686-1696.

12. Hecht SS (2005) Carcinogenicity studies of inhaled cigarette smoke in laboratory animals: old and new. Carcinogenesis 26: 1488-1492.

13. Jõers A, Jaks V, Kase J, Maimets T (2004) p53-dependent transcription can exhibit both on/off and graded response after genotoxic stress. Oncogene 23 : 6175-6185.

14. Kanai M, Hanashiro K, Kim SH, Hanai S, Boulares AH, et al. (2007) Inhibition of Crm1-p53 interaction and nuclear export of p53 by poly(ADP-ribosyl)ation. Nat Cell Biol 9: 1175-1183.

15. Kapoor M, Lozano G (1998) Functional activation of p53 via phosphorylation following DNA damage by UV but not gamma radiation. Proc Natl Acad Sci U S A 95: 2834-2837.

16. Kau TR, Way JC, Silver PA (2004) Nuclear transport and cancer: from mechanism to intervention. Nat Rev Cancer 4: 106-117.

17. Kaustov L, Yi GS, Ayed A, Bochkareva E, Bochkarev A, et al. (2006) p53 transcriptional activation domain: a molecular chameleon? Cell Cycle 5: 489-494.

18. Kim E, Giese A, Deppert W (2009) Wild-type p53 in cancer cells: when a guardian turns into a blackguard. Biochem Pharmacol 77: 11-20.

19. Komlodi-Pasztor E, Trostel S, Sackett D, Poruchynsky M, Fojo T (2009) Impaired p53 binding to importin: a novel mechanism of cytoplasmic sequestration identified in oxaliplatin-resistant cells. Oncogene 28: 3111-3120.

20. Lavin MF, Gueven N (2006) The complexity of p53 stabilization and activation Cell Death Differ 13: 941-950.

21. Ling G, Wei Y, Ding $X$ (2007) Transcriptional regulation of human CYP2A13 expression in the respiratory tract by CCAAT/enhancer binding protein and epigenetic modulation. Mol Pharmacol 71: 807-816.

22. Meek DW (2009) Tumour suppression by p53: a role for the DNA damage response? Nat Rev Cancer 9: 714-723.

23. Nie L, Sasaki M, Maki CG (2007) Regulation of p53 nuclear export through sequential changes in conformation and ubiquitination. J Biol Chem 282: 14616-14625.

24. Russo P, Paleari L, Granone P, Cesario A, Pastorino U (2008) Computed tomography screening for lung cancer in a high-risk population: update on current status. J Natl Cancer Inst 100: 1043-1044.

25. Ryan KM, Phillips AC, Vousden KH (2001) Regulation and function of the p53 tumor suppressor protein. Curr Opin Cell Biol 13: 332-337.

26. Schlamp CL, Poulsen GL, Nork TM, Nickells RW (1997) Nuclear exclusion of wild-type p53 in immortalized human retinoblastoma cells. J Natl Cancer Inst 89: $1530-1536$

27. Solozobova V, Rolletschek A, Blattner C (2009) Nuclear accumulation and activation of p53 in embryonic stem cells after DNA damage. BMC Cell Biol 10: 46. 